\title{
Principal Investigator' Perceptions of Effective Academic Leadership in Chinese Research Institutions and Universities
}

\author{
Xiaoyao Yue ${ }^{1}$, Yan $\mathrm{Ye}^{1}$, Xu Zheng ${ }^{2} \&$ Yanan Yang ${ }^{3}$ \\ ${ }^{1}$ Graduate school of education, Stamford International University, Bangkok, Thailand \\ ${ }^{2}$ School of Foreign study, Shaoguan University, Shaoguan, Guangdong, China \\ ${ }^{3}$ Real learning Institution, Bangkok, Thailand \\ Correspondence: Xiaoyao Yue, Graduate school of education, Stamford International University, Bangkok, \\ Thailand. E-mail: xiaoyao.yue@stamford.edu
}

Received: July 18, 2021

Accepted: August 20, $2021 \quad$ Online Published: August 30, 2021

doi:10.5539/jel.v10n5p122

URL: https://doi.org/10.5539/jel.v10n5p122

\begin{abstract}
Academic leadership is considered a key factor in university and research institute development. In a competitive environment, the role of academic leadership has become increasingly important. At present, China is committed to building world-class universities and advanced research institutes, while academic leadership is one of the key factors. Thus, what is the ideal academic leadership in China's institutional environment? What professional qualities should principal investigators have? This study investigates these issues with in-depth interviews of six principal investigators. The finding shows that the definition of academic leadership by principal investigators refers to academic expertise, assigning the team member, setting a direction, academic social skills, managing team member relationships, boosting team morale, and teamwork skills. Furthermore, academic expertise is often supposed to be more important than other abilities. In terms of competence, the definitions of leadership by Chinese principal investigators and the literature on Western academic leadership are similar.
\end{abstract}

Keywords: academic leadership, principal investigator, academic leader, research university

\section{Introduction}

In the past decade, leadership research has continued to develop in higher education, and most of the research focuses on individuals who hold formal management positions at higher levels, such as university presidents, school directors, and provosts. Scholars appoint professors, researchers, and administrators who have made significant contributions to the performance and development of the university, and translational research focuses on these groups (Meng, Tan, \& Li, 2017).

Two opposing paradigms influence the success of an organization-leadership and management. These two paradigms are generally recognized as institutions of academic governance in the field of higher education. Management, often considered less than ideal, has been described in higher education terminology as intrusive, restrictive, and based on unnecessary administrative tasks related to functional effectiveness and efficiency. On the other hand, leadership is collaborative, focusing on setting and motivating others in new directions, combined with achieving established and common goals, to promote high-quality teaching and learning (Parrish, 2013). Leadership is an important part of a position with supervisory responsibilities in any organization. This is the element that the organization relies on to transform goals into achievements (Simon, 1976). Also in the higher education era, research on the characteristics of effective formal leadership and management confirms that leaders and leadership are essential to improve the governance, learning, teaching, relevance, and success of higher educational institutions (HEIs) (Bryman, 2009; Bryman, 2007; Hofmeyer, Brenda, Klopper, \& Warland, 2015).

In the neoliberal culture that defines $21^{\text {st }}$-century colleges in developed countries, research performance is the main task of research-intensive universities and universities with research aspirations. Performance indicators such as Australia's research excellence in Australia, New Zealand's performance-based research funding activities, and the UK's Research Excellence Framework (REF) have placed research quality and productivity at the top of the institutional development agenda, making research an important priority. Outstanding activities must be dedicated to people and advance the goals and missions of the organization. The focus of these activities 
is to build research capabilities and train researchers. Therefore, academic leadership seems to be a reasonable, and even indispensable, specialized form of higher education leadership. Implicit in the university's formal leadership and management structure is the recognition of its value. There are obvious designated academic leadership roles at all levels of the institutional hierarchy, from senior managers to teachers and departments. But in a sense, such leadership research is insufficient, because their available knowledge base is very limited. Although academic leadership is considered important, it is still largely uncharted territory. There is still a big gap in the understanding of academic as an activity and academic leadership, and there is a lack of such research (Evans, 2014). Since the professor is almost completely correct in the research (Evans, Homer, \& Rayner, 2013), most of the knowledge about the professor is derived from anecdotes.

What is the effective leadership of academic leadership in China's research institution and university context? How do principal investigators view their roles, and what skills and qualities do leaders consider as essential to effective and efficient team management? This study uses in-depth interviews of six principal investigators and combines relevant studies to explore the aforementioned issues. In recent years, research on Chinese academic leadership has become increasingly abundant, but to the best of our knowledge, this work is the first to study the perception of ideal leadership by principal investigators themselves.

\section{Literature Review}

\subsection{Academic Leadership}

Academic Leadership research has centered on senior academic staff who have a formal leadership role (Laing, Laing, \& Gregory, 2011; Anthony \& Antony, 2017). The role of academic leadership: (a) Provide and protect an environment where productive academic work can be carried out; (b) Support and develop common academic values and sense of identity; (c) Represent individuals and working groups to achieve "cross-border". The boundary here refers to the ability to create opportunities for external relations, complete work through institutional management, and guide team members to enter a broader field of participation (Bolden, Gosling, O'Brien, Peters, Ryan, \& Haslam, 2012). Evans (2015b) mentioned that academic leadership requires the following three types of qualities: 1) Outstanding, by demonstrating outstanding professional knowledge and academic achievements both domestically and internationally; 2) Knowledge, outstanding academics have extensive methods and teaching knowledge, as well as authoritative subject knowledge; 3) Interpersonal relationships are manifested as kindness, kindness, and approachability, and senior figures are willing to help young colleagues in the academic development.

Academic leadership includes a range of different higher education roles, including different positions and titles. It usually ranges from tactical management centered on specific goals, relationship- and task-oriented administrative management, and vision-driven and potentially transformative leadership changes (Cheruvelil \& Montgomery, 2019). Academic leaders can adopt many different leadership styles. Many academic leaders enter departmental and other leadership levels through faculty. The promotion of tenure or non-tenure faculty members can put individuals in a position to consider leadership roles (Montgomery, 2020).

Leadership depends on the behavior of the leader. Teaching and research have been embedded in the core of the academic leadership function, sometimes referred to as teaching or intellectual leadership. Teaching leaders are renamed, learning leaders. Concurrently, academic leaders also play the role of managers. They focus on tasks, functions, and behaviors. When they act as managers, they promote the work of team members. Academic leaders play four management roles: activity management, resources, change, and self (Banker \& Bhal, 2020). This research is the first to explore the academic leadership of Chinese principal investigators.

\subsection{The Leadership for Principal Investigators}

Practice will ultimately affect the quality and completeness of the research. However, the leadership and management roles in the study have not yet been empirically tested. Semi-structured interviews conducted with 32 genetic researchers funded by the National Institutes of Health (NIH) revealed that they believe that leadership and management are essential for effective research, but their scientific training is not enough to prepare them. These findings suggest best practices in the research community, the future direction of scientific training, and enlightenment for scientific leadership and management research. In general, it is important to consciously adopt leadership and management practices and continue to improve them throughout your career. The basic element of this work is to openly accept feedback from laboratory members and suggestions from peers and colleagues. In addition, various methods must be kept in mind to coordinate and monitor the work of research team members. Important practices include promoting open communication and regular meetings, especially to solve problems. It is also important to balance individual needs, provide appropriate guidance, and allow independence at the same time. Finally, it is prudent to measure and monitor the atmosphere or culture of 
the working group in the laboratory to cultivate creative, honest, and productive employees. Scientists, especially those early in their careers, should look for available resources and training opportunities. Finally, for principal investigators, it is important to note that their behavior and practices as laboratory directors and research mentors can have a lasting impact on the personnel in their laboratory (Antes et al., 2016). As the person in charge of the laboratory, you need to be responsible for fundraising, fund management, purchasing materials and equipment (some of which are very professional and even unique), training and managing personnel who use hazardous materials, publicizing current research, and planning for the future the study. As a teacher, you need to inspire and educate the next generation of a series of teaching styles. Another key skill is to learn how to work with people and gain management experience before starting your laboratory (Tregoning \& McDermott, 2020).

A research team is made up of various people. How leaders deal with them, their concerns, requirements, and development are crucial. If a principal investigator makes a promise to someone, be sure to keep it, and it's best to record it in writing. If the situation changes and the leader is unable to complete it, please notify the person immediately and determine how to satisfy them in other ways. If the leader does not keep his promise, he will lose the trust of the team, which will be a heavy blow to his leadership authority. Tell team members the difference between "must" do something and when they "want them" to do something. The former informs about the consequences if you do not comply. The latter requires the consent of the other party. If there is no definite result, please don't try to force someone to do something (Detsky, 2011).

\subsection{The Characteristics of Effective Academic Leadership}

An academic leader is someone with a broad vision of their field, and who has the power to bring change in their field. They have the ability and capacity to release and engage human potential in the pursuit of a common cause They must sustain change and this energy must come from within the academic unit, driven by the vision of its leader. Academic units and institutions are particularly challenged in achieving unity around a focused mission because of the independent mindset that pervades academic culture: leadership is, therefore, a personal, face-to-face concept. Thus, the strategic planning process becomes an opportunity to mobilize and bring together stakeholders in pursuit of a mission (Mehood et al., 2012; Anthony \& Antony, 2017). The most effective academic leaders are characterized by overly ambitious, relaxed, ambitious, and passionate. The least effective characteristics are lack of ambition, confusion, ambiguity, and insecurity (Rehbock et al., 2019). A study of 28 senior female academic staff at Monash University in Australia found that many factors are critical to the research performance of university scholars (Dever et al., 2006). The most common are: High enthusiasm; Have good international connections and networks; Have effective instructors; Participate in cooperative research; Guide graduate students; Appropriate participation in administrative duties.

Based on the innovative concept of scientific teams, encourage leaders who are committed to innovation in organizations to enhance their team capabilities. Employees in higher education should value and adopt dialectical leadership methods, such as delegation and guidance, closeness and alienation, and the conversion between internal and external investment. The same may be true for the heads of other organizations: academic leaders have a high degree of complexity and desire for autonomy. Leaders do not need to identify ideas and innovations but need to create favorable conditions for effective teamwork. One way to do this is to enhance the reflexivity of the team, the extent to which the team reflects and changes its functions. During the reflection process, team members openly shared their views on team achievements and shortcomings in the current project. Transformational leadership is a feasible way to improve team reflection ability, which in turn is directly proportional to team performance. As another method, leaders can directly involve their team members in the leadership process to promote autonomy and participation. To be able to "share leadership", leaders need to create an internal team environment where team members can experience common goals, support each other, and have a free voice to express opinions (Braun et al., 2016).

\subsection{The China Context}

In 2000, the internationally accepted principal investigator system was fully established in key areas of China's basic sciences. The principal investigator is the representative of outstanding scientific and technical personnel, the leader of the scientific research team, the organizer and implementer of scientific and technological innovation. How to be the PI of the scientific research team is not only related to the individual development but also directly related to the team and the smooth progress of scientific research. To become an excellent leader of a research team, to live up to the responsibilities given by the times, you need to practice the following four "powers": strong responsibility, keen foresight, solid cohesion, and excellent learning ability (Zhao, Liu, Ren, \& $\mathrm{Wu}, 2017)$.

The concept involving scientific and technological talents is generally reflected in the elaboration of the system 
of leading scientists, strategic scientists, and scientific and technological talents. Its basic characteristics and connotations mainly include the following five points: (1) Has made outstanding contributions to the development of science and technology (discipline), and its achievements are as follows: It is recognized by the society as being able to lead and guide the sustainable development of corresponding disciplines; (2)Have a strategic vision, have an overall view of the overall situation, be good at grasping the needs of human society or national development strategies and the laws of scientific and technological development, have insights into the frontiers of international scientific and technological development, and have excellent scientific and technological leadership; (3)Have cross-disciplinary knowledge and strong creativity; (4)Be good at cultivating, motivating, and bringing up a large number of outstanding scientific and technological talents, leading scientific and technological research teams or organizing continuous innovation to form a sustainable competitive advantage in science and technology; (5)Having a scientific spirit of seeking truth and being pragmatic And a strong sense of social responsibility and mission (Tan, 2015).

\section{Research Methods}

The author collected situational data based on on-site semi-structured interviews and a content analysis method was used to analyze the interview data. Researchers used NVivo 12 to analyze data, generate codes, and summarise related themes. The interviews focused on the PI perceptions and definitions of leadership. The outline of each interview is based on Shen, Huang, and Fan's (2020) study. They put forwards four questions for the ideal leadership of academic leaders. The researcher deleted the first question that was unsuitable for this study. Thus, the interview consists of three questions:

(1) How can PI do a good job in their team? What key areas require attention? What kinds of relationships and issues should be addressed?

(2) What is competency, quality and standards should an ideal PI have? Provide some typical examples that can reflect the aforementioned ability, quality, and standards.

(3) As a PI, which do you think is difficult to handle, but at the same time, is important?

PI is mainly concentrated in research universities and research institutes. This research mainly focuses on research universities and research institutes. In 2020, the researchers interviewed six PI from both the research universities and research institutes in China, with each interview lasting about 20-30 min. one was female, and five were males. All six PI have Ph.D. degrees, of which all have a background in engineering and science. All of them are professors and have an academic team. All of the interviewees continued to supervise doctoral students. To protect the privacy of interviewees, everyone is assigned a letter, A-F, according to the order of interviews. When quoting the interview texts below, the researcher only indicated the letter assigned to the interviewee (i.e., from A to F).

\section{Discussion}

\subsection{Data Analysis and Discussion}

Base on the data analysis of NVivo 12, the codes came from six interviewees (Figure 1). It can be seen from the figure that the codes mainly come from interviewees A, F, and E. Figure 2 shows the results of coding, including academic expertise, assign the team member, set a direction, academic social skills, manage team member relationships, boost team morale, and teamwork skills. Table 1 shows the summary of codes.

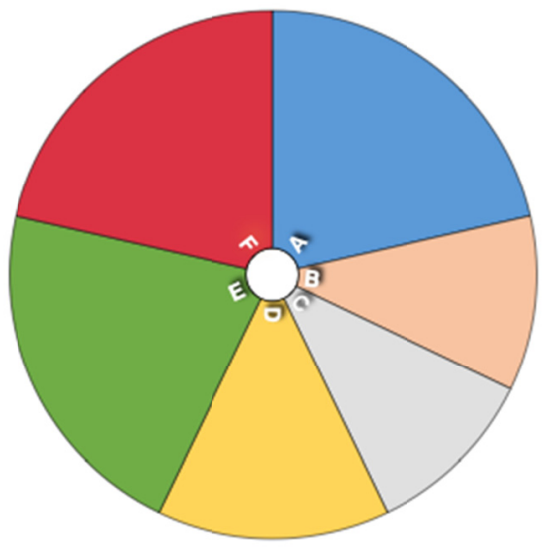

Figure 1. Coding for files 


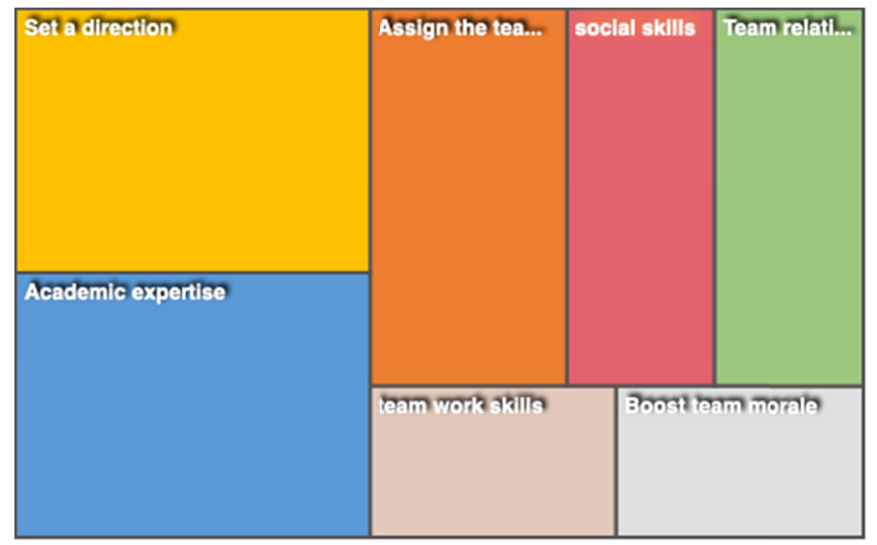

Figure 2. Coding for notes

The management styles of the sample of PI vary from person to person, and the same person may use different management methods at different times in different situations. Nevertheless, all these leaders recognize that there is a set of core qualities that are essential to effective and efficient leadership. In other words, the group's expectations of themselves as PI are highly consistent. Due to space limitations, we will only discuss a few selected core qualities.

Table 1. Summary of codes

\begin{tabular}{ll}
\hline Codes & Number of codes \\
\hline assign the team member & 5 \\
set a direction & 5 \\
academic expertise & 5 \\
Academic social skills & 4 \\
manage team member relationship & 3 \\
boost team morale & 2 \\
teamwork skills & 2 \\
\hline
\end{tabular}

\subsection{Academic Expertise}

Academic leaders are usually selected based on their success in research. In this way, they won the respect of the researchers in their units (Detsky, 2011). University management is different from government management. In terms of knowledge production and dissemination, the academic status of university leaders will have a direct impact on their management authority. The professional knowledge and literacy of university leaders will also directly affect their management efficiency (Goodall, 2009).

Modern researchers must have sufficient resources and creativity to transform their hypotheses or conjectures into achievable research projects. Moreover, they must acquire excellent measurement tools and knowledge of related fields of technology. When they explain and present the results, they must be accurate and honest. Wrong interpretations and even data tampering will not simply lead to deviation and invalidity of future research (Stefanadis, 2006). The future results of researchers are based on their academic knowledge and the impact of post-doctoral education on knowledge. Education has been used to measure the level of knowledge of researchers, although the diversity of educational backgrounds should be kept in mind. Some scholars believe that experience is part of the knowledge of researchers. An in-depth understanding of the problem being studied constitutes the capital of top researchers. Moreover, if there is not enough knowledge, the study may be rejected (Foncubierta-Rodríguez et al., 2020).

Academic leaders should be technical experts in their research field (Interviewer C and Interviewer F) and have frontier vision (Interviewer A). The ideal PI should first be a person with strong scientific research ability because the most important indicator reflecting the performance of a research group is publication and funding. Only PI with strong scientific research ability can drive the development of the team (Interviewer D).

Knowledge is an indispensable quality for researchers because the entire research project depends on it. Knowledge equals progress, and at the same time equals innovation and discovery. Knowledge is the essence of 
any research progress. Knowledge is the main foundation of research (Toledo-Pereyra, 2012).

Academic leadership has contributed to the promotion of the development of disciplines and institutions as well as the academic profession. The academic contribution of academic leaders is the most important (Baris \& Anthony, 2018).

Having many years of experience in this field, showing strong research performance, and exhibiting major outstanding contributions in their respective disciplines or professional fields play leading roles (Interviewer E)

\subsection{Assign the Team Member}

Leadership is an important human activity that can make an organization successful without letting it stagnate or get lost. Leadership is a process of social influence, where one can get help and support from others and complete a common task (Davalos, 2016; Chemers, 1997). There are many aspects to running a successful laboratory, including the elements of luck, imagination, and opportunism. And hard work. However, the most important thing is the people in the team. They deserve PI's full attention and need to feel that PI supports them (Banks, 2021).

Reasonably allocate multidisciplinary scientific research personnel to work together to achieve short-term and long-term goals, and rationally allocate and explore the capabilities of the outstanding researchers (Interviewer B). Assign the team member with their matched skill (Interviewer C), but PI must be good at assigning tasks (Interviewer F).

Teamwork in organizations has increasingly become a norm, but the challenge of working effectively in a team is huge. One of the challenges is conflict, that is, the tension between team members due to actual or perceived differences (De Dreu \& Weingart, 2003). As an academic leader, you should set the roles and tasks of each individual by the goals of the team. Team leaders should build the team based on diversity and value the differences between people. Leaders should recruit talents, encourage the development of personal abilities, and train colleagues, as far as possible not to be threatened by people with special abilities (Meng, Tan, \& Li, 2017). PI needs to promote the collaboration of the research team and mentor the team members. PI is also responsible for the performance level of its members. Leaders should have the ability to enhance scientific cooperation and teamwork between members of the research or project team and the ability to analyze the information obtained (Foncubierta-Rodríguez et al., 2020). Another important aspect of the academic leadership of senior scholars is to guide doctoral students' research during their studies and contribute to the academic development of other young colleagues in the team. Last but not the least, providing support and funding to the team members is also crucial (Baris \& Anthony, 2018).

There are also teaching post teachers in the team, and it is necessary to master the balance of each teacher so that teachers who are partial to scientific research posts and partial teaching posts can give full play to their advantages and achieve efficient scientific research and teaching output within the team (Interviewer D).

\subsection{Set a Direction}

Academic leaders should prioritize tasks and have clear research directions (Hemmings, Hill, \& Sharp, 2013). The person in charge needs to determine the team's vision and consensus, and others can take action according to their wishes (Meng, Tan, \& Li, 2017). Ramsden (1994) defines academic leadership as several responsibilities, including leadership in teaching, research, or planning vision. Academic leadership establishes academic direction and achieves common goals by empowering team members. This definition assumes that the activities of these people must achieve the following ideal effects: (1) enhance the enthusiasm of scholars; (2) set direction; (3) empower others (Gmelch \& Wolverton, 2002). While focusing on teaching and learning, knowledge leaders will deal with intellectuals such as faculty, staff, and students, while instructive leaders will focus on long-term growth and progress by adjusting plans and guiding employees in the right direction (Banker \& Bhal, 2020).

The main job of PI in the team is to grasp the basic direction (Interviewer E), which can guide the development direction of the team (Interviewer A), and more importantly, finding the right direction, defining the right field, and setting the right research topic (Interviewer F). Give clear direction, set the milestones for each project (Interviewer C).

The scientific research team, like any small business, improves its influence and productivity by developing and executing strategic plans. This plan can be composed of different time scales, for example, short-term goals ( 3 to 6 months) and long-term goals ( 1 to 3 years). The plan is to achieve the vision and goals of the team. There are many ways to develop a strategic plan, but the recommendation should include at least four components: (1) the laboratory's mission statement; (2) what is most important now (3) how to achieve short-term goals; and (4) scientific development Long-term vision or plan (Paul \& Melanie, 2019). 
PI formulates short-term and long-term plans based on the research history and trends in this field and combines research hotspots, basic research, and industrialization feasibility to formulate 3-year, 6-year, and 9-year goals (Interviewer B).

\subsection{Academic Social Skills}

PI is responsible for the overall administrative, financial, scientific, and ethical aspects of the research project, and supervises researchers and students. Because PI can delegate tasks to members of the research team, PI is ultimately responsible for all aspects of research (Rajab et al., 2020).

At present, the more difficult problems to deal with are mainly the distribution of time and energy. How to coordinate the relationship between the outer academic circle and the growth management of one's academic team, as well as the balance and coordination of multiple tasks in academic, teaching, and nature are more difficult to grasp (Interviewer E).

The ability to address social problems and acquire resources has become increasingly important (Shen, Huang, \& Fan, 2020). Excellent academic leaders should provide social services to team members, including basic functions, such as bringing academic resources, increasing opportunities for research collaborators, guiding national policies, shaping the academic world, making it effective, and popular in the market (Dinh, Caliskan, \& Zhu, 2020). In the interview, several PI answers described the functions of social in more detail: PI must have a certain degree of academic socialization and the ability to obtain resources (Interviewer A). Academic leaders should have the ability to coordinate all aspects of the relationship, including internally and externally. Internally, team members should collaborate and develop together. Externally, they should strengthen communication and increase the exposure and visibility of the team and PI outside. This is in line with publication and funding can complement each other. The current disciplines are becoming more and more intertwined. If you want to make better scientific research, you must strengthen foreign cooperation. This feature has been very prominent in terms of co-publishing articles and co-application projects (Interviewer D).

\subsection{Manage Team Member Relationship}

If the physiological and safety needs are met, then the desire for relationships and connection with people are the next basic requirements in Maslow's (1943) well-known hierarchy of needs motivation theory. Specifically, people may want to have a sense of belonging or find their place in the group. This strong desire may be more valuable than a person's self-esteem. Relationships establish a sense of community and are an important part of human nature and emotions (Conner, 2015).

The quality of the relationship between individuals and their team members is called team member exchange. The review of empirical research shows that TMX can improve personal performance and team operation ability because individuals in high-quality TMX relationships are more willing to help each other and share information, ideas, and feedback within the work team (Tse \& Dasborough, 2008).

The relationship between team members is a very important issue. (Interviewer F). Academic leaders should coordinate team relationships to ensure that team members play an appropriate role. What needs attention is how to coordinate the overall view of the whole team and the personal interests of team members when they are inconsistent interests (Interviewer E). In the team, since the students and teachers, and PI are not too old, everyone is also a teacher and a friend. I think the atmosphere and atmosphere of tension, unity, and mutual help within the team are necessary (Interviewer D).

\section{7 Boost Team Morale}

Team morale was defined in the study as the collective attitude and joint commitment of members in terms of team tasks (Lindsay, Manning, \& Petrick, 1991). Leaders build a created team and develop great morale with respect, honesty, love, and spirituality empower employees (Autry, 2007). Teams with high morale have a strong sense of team responsibility and commitment to peak performance, and have a continuous social influence on team members because their team members usually expect to collaborate under the guidance of team interests. On the contrary, team members with low team morale will be affected by weaker social influences and have limited constraints on their private behavior (He, 2012). Kappelman, McKeeman, and Zhang (2006) stated: Project team members who lack a commitment to the scope and schedule of the project will always find other worthwhile activities." In short, team morale will offset the free-riding trend in the project team.

Boost the morale of the team. For a team, the most important thing is the human problem (Interviewer F). The initiative of a scientific researcher is a difficult point, and it is also a condition for the continuous development and vitality of a team (Interviewer B). 


\subsection{Teamwork Skills}

Academic leaders should provide a good institutional environment for team members, including opportunities to support the professional development of team members, and organizational culture for participating in team research (Hemmings, Hill, \& Sharp, 2013). Teamwork in organizations has become an increasing norm, but effective work in a team faces huge challenges (Guzzo \& Shea, 1992). Especially when the team performs complex tasks, the team is effective rather than personal task team efficiency also depends on the extent to which team members need to help each other, coordinate activities, comply with needs and requirements, and express opinions and ideas to avoid process losses. One of the challenges of team efficiency is conflict-Thomas, due to actual or perceived Differences lead to tension between team members. The interpersonal relationship is related, but the effect is sufficient, and the well-being and turnover rate are reduced. Time and energy allocation (De Dreu \& Weingart, 2003). Many studies by researchers aim to determine the factors most likely to affect research productivity. The assessment of the researcher's productivity usually includes the amount of input and output. Input measures include the value of the research funding received, mentoring doctoral students, helping colleagues develop ideas, and reviewing manuscripts. Output metrics include peer-reviewed journal articles, speeches, book chapters, and writings (Browning, Thompson, \& Dawson, 2017).

Have good teamwork skills (Interviewer E). Unite the team and gather strength. Academic leaders must have a broad mind and firm will to ensure that the entire team is twisted together (Interviewer A).

\section{Conclusion}

In the era of globalization, Chinese universities and research institutes face some common challenges as those the Western have. Analysis of the interview data indicate that the kinds of academic leadership recognized and expected by Chinese principal investigators are quite similar to those found in Western universities and research institutes as mentioned in the existing literature, such as academic expertise (Toledo-Pereyra, 2012), assigning the team member (Banks, 2021), setting a direction (Gmelch \& Wolverton, 2002), academic social skills (Dinh, Caliskan, \& Zhu, 2020), managing team member relationship (Conner, 2015), boosting team morale (Kappelman, McKeeman, \& Zhang, 2006), teamwork skills (Hemmings, Hill, \& Sharp, 2013).

Besides, Chinese principal investigators especially emphasize a good academic standing and expertise in a particular academic field, which are consistent with the idea of the PI in British universities (Detsky, 2011; Goodall, 2009).

\section{References}

Antes, A. L., Mart. A., \& DuBois, J. M. (2016). Are Leadership and Management Essential for Good Research? An Interview Study of Genetic Researchers. Journal of Empirical Research on Human Research Ethics, 11(5), 408-423. https://doi.org/10.1177/1556264616668775

Anthony, S. G., \& Antony, J. (2017). Academic leadership-special or simple. International Journal of Productivity and Performance Management, 66(5). https://doi.org/10.1108/IJPPM-08-2016-0162

Autry, J. A. (2007). The Servant Leader: How to Build a Creative Team, Develop Great Morale, and Improve Bottom-line Performance. Prima Publishing, Roseville, CA.

Banker, D. V., \& Bhal, K. T. (2020). Creating world class universities: Roles and responsibilities for academic leaders in India. Educational Management Administration \& Leadership, 48(3), 570-590. https://doi.org/10.1177/1741143218822776

Banks, L. (2021). Words of Advice: How to be a good Principal Investigator. The FEBS Journal, 288(13), 3973-3977. https://doi.org/10.1111/febs.15755

Baris, U., \& Anthony, W. (2018). The influence of universities' organizational features on professorial intellectual leadership. Studies in Higher Education, 43(3), 571-585. https://doi.org/10.1080/03075079.2016.1185774

Bolden, R., Gosling, J., O’Brien, A., Peters, K., Ryan, M., \& Haslam, A. (2012). Academic Leadership: Changing Conceptions, Identities and Experiences in UK Higher Education. Summary Report. London: Leadership Foundation.

Braun, S., Peus, C., Frey, D., \& Knipfer, K. (2016). Leadership in academia: Individual and collective approaches to the quest for creativity and innovation. In C. Peus, S. Braun \& B. Schyns (Eds.), Leadership lessons from compelling contexts (Monographs in Leadership and Management series, pp. 349-365). Bingley, England: Emerald. 
Browning, L., Thompson, K., \& Dawson, D. (2017). From early career researcher to research leader: Survival of the fittest? Journal of Higher Education Policy and Management, 39(4), 361-377.

Bryman, A. (2007). Effective leadership in higher education: A literature review. Studies in Higher Education, 32(6), 693-710. https://doi.org/10.1080/03075070701685114

Bryman, A. (2009). Effective leadership in Higher Education: Final Report. Leadership Foundation for Higher Education: UK.

Chemers. M. (1997). An integrative theory of leadership. Mahwah, NJ: Lawrence Erlbaum Associates, Publishers.

Cheruvelil, K. S., \& Montgomery, B. L. (2019). Professional development of women leaders. In C. M. Rennison \& A. Bonomi (Eds.), Women Leading Change in Academia: Breaking the Glass Ceiling, Cliff, and Slipper (pp. 235-254). San Diego, CA: Cognella Academic Publishing.

Conner, T. (2015). Relationships and authentic collaboration: Perceptions of a building leadership. Leadership and Research in Education: The Journal of the Ohio Council of Professors of Educational Administration, 2(1), 12-24.

Davalos, J. F. (2016). A Study of Academic Leaders in Two Large Alberta Universities. Unpublished doctoral thesis. University of Calgary, Calgary, AB. Retrieved from http://hdl.handle.net/11023/3474

De Dreu, C. K. W., \& Weingart, L. R. (2003). Task versus relationship conflict, team performance, and team member satisfaction: A meta-analysis. Journal of Applied Psychology, 88, 741-749. https://doi.org/10.1037/0021-9010.88.4.741

Detsky, A. (2011). How to be a good academic leader. Journal of General Internal Medicine, 26, 88-89. https://doi.org/10.1007/s11606-010-1486-7

Dever, M., Morrison, Z., Dalton, B., \& Tayton, S. (2006). When research works for women. Melbourne, Australia: Monash University.

Dinh, N., Caliskan, A., \& Zhu, C. (2020). Academic leadership: Perceptions of academic leaders and staff in diverse contexts. Educational Management Administration \& Leadership. https://doi.org/10.1177/1741143220921192

Evans, L. (2014). What is effective research leadership? A research-informed perspective. Higher Education Research and Development, 33(1), 46-58. https://doi.org/10.1080/07294360.2013.864617

Evans, L. (2017). University professors as academic leaders: Professorial leadership development needs and provision. Educational Management Administration \& Leadership, 45(1), 123-140. https://doi.org/10.1177/1741143215578449

Evans, L. (2015a). University Professors as Academic Leaders: Professorial Leadership Development Needs and Provision. Educational Management Administration \& Leadership. Advance online publication. https://doi.org/10.1177/1741143215578449

Evans, L. (2015b). A Changing Role for University Professors? Professorial Academic Leadership as it is Perceived by 'the Led'. British Educational Research Journal, 41(4), 666-685. https://doi.org/10.1002/berj.3163

Evans, L., Homer, M., \& Rayner, S. (2013). Professors as academic leaders: The perspectives of 'the led'. Educational Management, Administration and Leadership, 41(5), 674-689. https://doi.org/10.1177/1741143213488589

Foncubierta-Rodríguez, M. J., Martín-Alcázar, F., \& Perea-Vicente, J. L. (2020). Measuring the human capital of scientists in the principal investigator role. Journal of Management Development. https://doi.org/10.1108/JMD-08-2019-0362

Gmelch, W., \& Wolverton, M. (2002). An investigation of dean leadership. Paper presented at the annual meeting of the American Educational Research Association, New Orleans, LA.

Goodall, A. H. (2009). Socrates in the Boardroom: Why Top Scholars Should Lead Research Universities. New Jersey: Princeton University Press.

Guzzo, R. A., \& Shea, G. P. (1992). Group performance and intergroup relations in organizations. In Handbook of Industrial and Organizational Psychology (pp. 269-313), Psychologists Press: Palo Alto, CA.

He, J. (2012). Counteracting Free-Riding with Team Morale-An Experimental Study. Project Management 
Journal, 43(3), 62-75. https://doi.org/10.1002/pmj.21272

Hemmings, B., Hill, D., \& Sharp, J. G. (2013). Critical interactions shaping early academic career development in two higher education institutions. Issues in Education, 23, 35-51.

Hofmeyer, A., Brenda, H. S., Klopper, H. C., \& Warland, J. (2015). Leadership in learning and teaching in higher education: Perspectives of academics in non-formal leadership roles. Contemporary Issues in Education Research (Online), 8(3), 181-192. https://doi.org/10.19030/cier.v8i3.9348

Kappelman, L. A., McKeeman, R., \& Zhang, L. (2006). Early warning signs of IT project failure: The dominant dozen. Information Systems Management, 31-36. https://doi.org/10.1201/1078.10580530/46352.23.4.20060901/95110.4

Laing, L., \& Laing, G. K. (2011). The student as customer model and its impact on the academic leadership role in higher education. ATN Assessment Conference, Meeting the Challenges, 2011

Lindsay, W. M., Manning, G. E., \& Petrick, J. A. (1991). Mapping work group morale. Journal for Quality and Participation, 14(2), 100-106.

Maslow, A. (1943). A theory of human motivation. Psychological Review, 50, 370-396. https://doi.org/10.1037/h0054346

Mehmood, I., Khan, S., Baber, R. K., \& Tahirkheli, S. A. (2012). Role of academic leadership in change management for quality in higher education in Pakistan. Journal of Education and Practice, 3(16).

Meng, Y., Tan, J., \& Li, J. (2017). Abusive supervision by academic supervisors and postgraduate research students. International Journal of Leadership in Education, 20(5), 605-617. https://doi.org/10.1080/13603124.2017.1304576

Montgomery, B. L. (2020). Academic leadership: Gatekeeping or groundskeeping? Journal of Values Based Leadership, 13, 135-151.

Parrish, D. (2013). The relevance of emotional intelligence for leadership in a higher education context. Studies in Higher Education, 40(5), 821-837. https://doi.org/10.1080/03075079.2013.842225

Paul, L. G., \& Melanie, A. S (2019). Becoming a Principal Investigator: Designing and Navigating Your Academic Adventure. Neuron, 103.

Rajab, M. H., Gazal, A. M., Alkawi, M., Kuhail, K., Jabri, F., \& Alshehri, F. A. (2020). Eligibility of medical students to serve as principal investigator: an evidence-based approach. Cureus, 12, 7025.

Ramsden, P. (1994). Current challenges to quality in higher education. Innovative Higher Education, 18, 177-188. https://doi.org/10.1007/BF01191112

Rehbock, S. K., Pircher, V. A., \& Knipfer, K. (2019). Rate my professor: Implicit leadership theories in academia. Stud. Higher Educ., Epub ahead of print.

Shen, W. Q., Huang, Y., \& Fan, W. (2020) Morality and ability: institutional leaders' perceptions of ideal leadership in Chinese research universities. Studies in Higher Education, 45(10), 2092-2100. https://doi.org/10.1080/03075079.2020.1823645

Simon, H. A. (1976). Administrative Behavior: A Study of Decision-Making Processes in Administrative Organization (3rd ed.). Free Press, New York, NY.

Stefanadis, C. I. (2006). Characteristics of the good researcher: Innate talent or acquired skills? Hellenic Journal of Cardiology, 47, 52-53.

Tan, H. J. (2015). Research on the leadership of science talents. Leader Science.

Toledo-Pereyra, L. H. (2012). Ten qualities of a good researcher. Journal of Investigative Surgery, 25, 201-202. https://doi.org/10.3109/08941939.2012.701543

Tregoning, J. S., \& McDermott, J. E. (2020). Ten Simple Rules to becoming a principal investigator. PLoS Comput Biol., 16(2), e1007448. https://doi.org/10.1371/journal.pcbi.1007448

Tse, H. H. M., \& Dasborough, M. T. (2008). A study of exchange and emotions in team member relationships. Group \& Organization Management, 33, 194-215. https://doi.org/10.1177/1059601106293779

Zhao, H. X., Liu, Y. X., Ren, W., \& Wu, H. X. (2017). The Basic Conditions that the Principal Investigator Should Have. Management for Economy in Agricultural Scientific Research, 1, 22-24, 28. 


\section{Copyrights}

Copyright for this article is retained by the author, with first publication rights granted to the journal.

This is an open-access article distributed under the terms and conditions of the Creative Commons Attribution license (http://creativecommons.org/licenses/by/4.0/). 